\title{
A Study on Campus Site Selection-- Application of AHP with MCDM and Group Decision Making --
}

\author{
Long-Chuang Wang \\ Department of Civil Engineering, Division of Transportation Engineering. National Central \\ University, Chung-Li, Taiwan, R.O.C. Tel: 886-3-4267254; FAX: 886-3-4254604
}

Tzay-An Shiau

Department of Traffic and Transportation Engineering and Management, Feng Chia Unversity. 100

Wen-hua Rd. Taichung, Taiwan, R.O.C.

How-Ming Shieh

Department of Civil Engineering, and Information Management, National Central University, Chung-

Li. Taiwan, R.O.C.

\begin{abstract}
Three major stages are identified to perform campus site selecti-on process The first stage uses a screening model to screen out the conspicuously inadequate candidate campus sites based on noncompensatory criteria, including formative and negative conditions. The second is the stage for detailed evaluation. A multicriteria evaluation model is employed to trade-off the weights for compensatory relationship. The analytic hierarchy process (AHP) and the permutation method systemize and stratify the complicated problem The results are then compared pairwisely and quantified to perform a synthetic evaluation. The compromise programming is employed in the third stage to coordinate the viewpoints of various representative interests for public issues.
\end{abstract}

Keywords: Location, analytic hierarchy processes, screening model, multiple criteria analysis, multiple objective decision making.

\section{Introduction}

Accompanying with economic growth and increase of personal income per capita in Taiwan area, total number of newly established and scale-enlarged high educational institutes has significantly increased in the past ten years. The seiection of appropriate campus sites therefore becomes very important issues for these high educational institutes. The principal factors that may influence the selection may include objectives of the institutes, inter-relationship to society, high education resource allocation, and regional development. The multifacet characteristics of campus site selection leads the way of solution techniques to integrate analytic hierarchy process(AHP); permutation method, muliti-criteria decision making (MCDM) and group decision making.

The selection procedures are then applied to the campus site selection for National Taipei Institute of Technology. The results are found to be satisfactory. As a closure, the employed sequential decision processes are found robust and reliable concerning the integration of AHP and permutation method with MCDM. Representative interests, expert objectiveness and spirit of democracy are also compromised by group decision making. The analytical results can also provide decision makers with the second best solution in combination with optimal solutions of group decision making individually. It is expected that the exemplified procedures are 
of flexible and effective decision support tools for campus site selection and other similar occasions.

2. Establishment of multiple objective decision making analysis model for public facility location

According to the characteristics of public facility location problem, this study will employ a three stages analysis structure to establish multiple objective decision making analysis model for public facility location. The first stage is of the screening model which takes mutually non-compensable criterion as its screening requirement, and that includes affirmative and negative provisions. For instance, the land acquisition of public college and university must abide by the guideline of non-compensable donation, and any location that runs against such principle will be taken as infeasible and have to be eliminated, thus "non-compensable donation" is of negative provision. On the other hand, highway is constructed as well to work with the demand of international transportation, so highway interchange should be set up at spots where there are international airport or harbor so as to facilitate connection, and those locations that conform to such requirement should be singled out as decision making alternatives, as a matter of course, "international airport or harbor" is of affirmative provision. Of those canvassing locations that have gone through screening model, they share such mutual trade-off and complementary relationships under multiple criteria evaluation environment, and so they are evaluated by the multicriteria evaluation model, which is the analysis model of the second stage. The third stage is of group decision making model which is contrived focusing on decision making problem (public facility location problem is of the kind) of public affairs, and the model is intended to integrate representative opinions of various backgrounds so as to obtain compromise altemative for citation in decision making. The flowchart of analysis is as shown in Figure 1.

The first stage is of the initial evaluation stage which does not demand for prudent mathematical method for resolution; the second stage is of detailed evaluation stage and only through the operation of discriminating mathematical method can it systemize and clarify complicated decision making problem, and can render result more reliable. Thus, this paper has studied two MCDM methods as AHP and permutation method for integration and applied them onto the second stage evaluation model. The operation of qualitative and quantitative criteria are applicable in AHP as the method is easy to operate and is well founded with theory, thus it is widely utilized in social sciences. This study has used AHP to investigate the preference structure of subjectiveness.

Permutation method can handle quantitative as well as qualitative criteria simultaneously, besides, it enjoys the advantage of procedure administration with robustness, thus, this study employs this method to evaluate those canvassing locations after screening. The third stage is of the group decision making model, and this study utilizes compromise programming to resolve for solution, since it has such advantage as its resolved result relishes compromise effect and is nearest to the preference solution of each member of the decision making group, the derived solution can be more acceptable to everyone. 


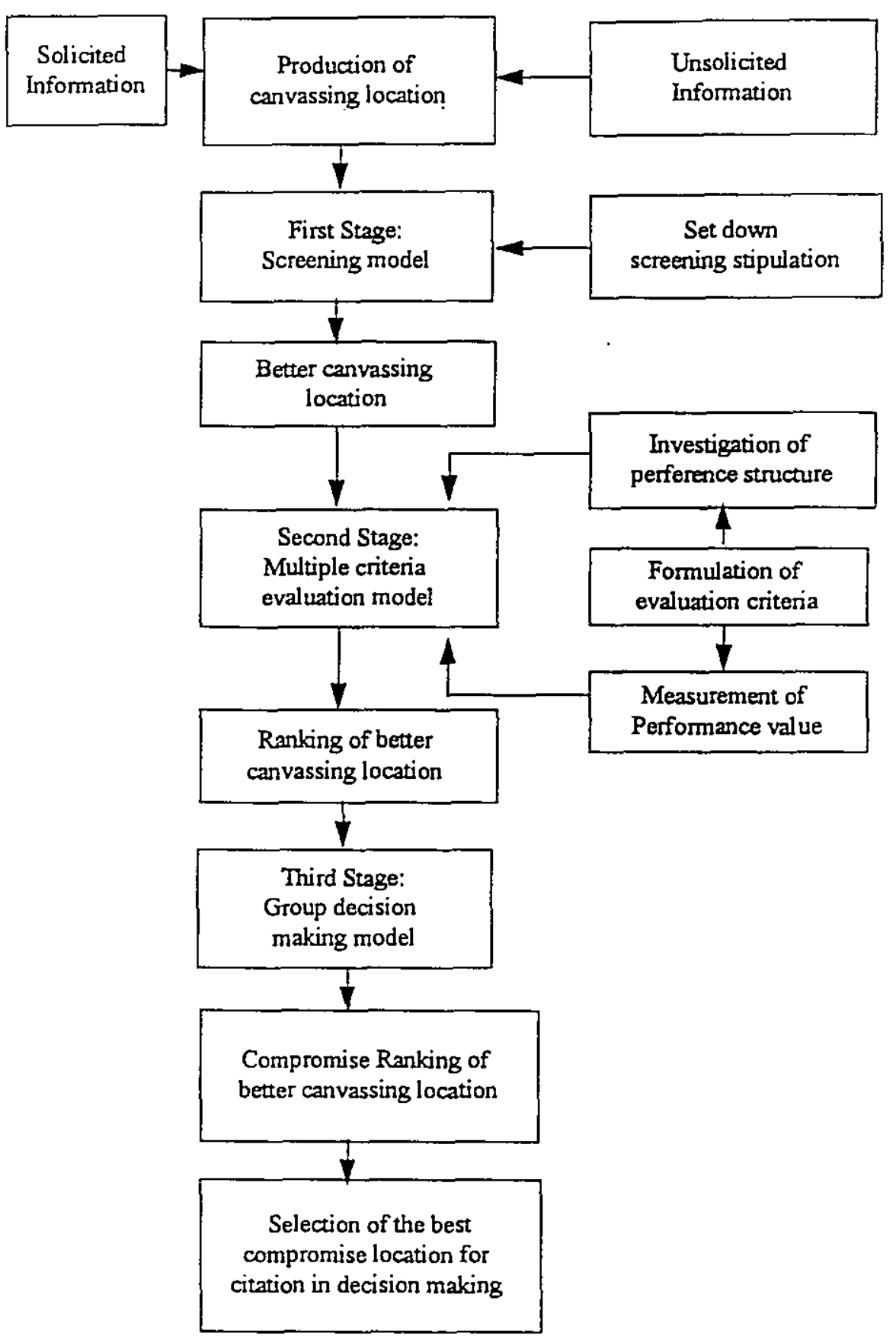

Figure 1. The Flowchart of Multiobjective Decision Making Analysis for Public Facility Location 
3. Mlustration study -- evaluation analysis for the new campus site of Taipei Institute of Technology

All of these newly-established or upgraded college and university face the selection problem of new campus site. Since this problem is inherently of public facility location problem multiobjective decision making analysis model for public facility location is suitable to be utilized in this part for resolution. This study has, therefore, employed the evaluation and selection of new campus site for Taipei Institute of Technology to conduct illustration analysis, and the analyzed results can, on one hand, be cited as references for Taipei Institute of Technology and related educational authorities, while its analysis procedures can, on the other hand, be referred by other college and university and other public department when they are to select the location for public facility.

\subsection{The screening of canvassing locations for the new campus site of Taipei Institute of Technology}

Taipei Institute of Technology has officially set up the "preparatory work planning team for college upgrading" with the instruction from the ministry of education in 8th August, 1990, and the team is steered by its principal. Under this team, there is the land programming unit which is in charge of the evaluation and selection of new campus site as well as land acquisition. And within about a year's time, this unit has obtained information on twenty-six designated spots of areas for new campus sites.

Four better canvassing locations have been selected from these twenty-six designated spots of areas for new campus sites after the operation of the screening model, which are L1, L2, L3, and L4.

Since these four designated spots of areas enjoy respectively their ups and downs under multiple requirements and they also share mutual trade-off, it has become such a necessity that only serious theoretical analysis can help determine which is of the optimal location. As a result, this study will further utilize multicriteria evaluation model and group decision making model to evaluate in detail these four better canvassing locations, which is as indicated in the following section.

3.2 Multiobjective decision making analysis of the optimal compromise location of the new campus site for Taipei Institute of Technology

As can be learned from preceding section, there are altogether four better canvassing locations that comply to the requirements as land acquisition, land size, geology and shape, transportation condition, and climate environment for the new campus site of Taipei Institute of Technology after the initial screening, and this study will further used multiobjective decision making analysis methods to conduct detailed evaluation so as to select the best compromise location for citation in decision making. 


\subsubsection{Formulation of evaluation criteria}

According to the definition of Zeleny, decision making is the measurement standard for auxiliary decision making (Zeleny, [1] ), and it is directed 'by' attribute, objective, and goal. Thus, attribute, objective, and goal can all, if expounded broadly, be taken as a kind of criterion.

Due to the fact that evaluation criterion is one of the four elements in decision making, the scope of it will have to depend on the characteristics of the decision making problem while the basic principles for criteria formulation are common. Keeney and Raiffa singled out five following principles (Keeney and Raiffa, [2] ):

\section{Completeness}

Important characteristics related to the decision making problem should be embraced.

\section{Decomposable}

For related items in different hierarchies, decomposable practice can be employed so as to simplify the process of evaluation.

\section{Operational}

Criterion should be meaningful to decision maker and can be opened for public discussion.

\section{Nonredundancy}

When a certain criterion is capable of indicating other criteria, other criteria should be discarded so as to avoid repeated calculation of the same performance.

\section{Minimal size}

The minimal size of criteria is employed to evaluate practical issues so as to simplify evaluation process.

Upon preceding principles, evaluation criteria are mostly formulated by hierarchical analysis and that will systemize and clarify the decision making problem. As a matter of fact, hierarchical analysis is actually the basic tool of human thinking (Komoda et al., [3] ), and its three steps are:(1) to identify the basic element of the problem; (2) to classify basic elements; (3) to arranged these classified elements into hierarchies.

The simplest hierarchical analysis can be conducted by linear administration nunning from higher-level analysis to lower-level, or vice versa, and the application of AHP method, developed by Saaty[4], on decision making problem has, in all cases, exploited such kind of practice. Furthermore, when elements of different hierarchies share cycle relationship, the manner of linear administration could no longer handle such kind of problem and the problem has to be administered by other sophisticated methods, such as PPDS (planning procedure to development systems)(Komoda et al., [3] ), HSA (hierarchical structure analysis) and so on.

And how can the formulated criteria be made more accommodating to practical problem? Keeney and Raiffa considered that through brainstorming method as well as with integration of various expert opinions can help obtain, in most of the 
situations, the anticipated results (Keeney and Raiffa, [2] ). MacCrimmon suggested that one could have learn the techniques of administration from relevant literatures (MacCrimmon, [5] ). Based upon the above-mentioned analysis, this study will employ five aspects as policy, society, economics, environment and transportation to consider, as a whole, the evaluation of canvassing locations for new campus sites, and these five aspects are furthered into fourteen criteria which are as shown in Figure 2. The significance and its measurement manner of each of the evaluation criteria are respectively elaborated as following.

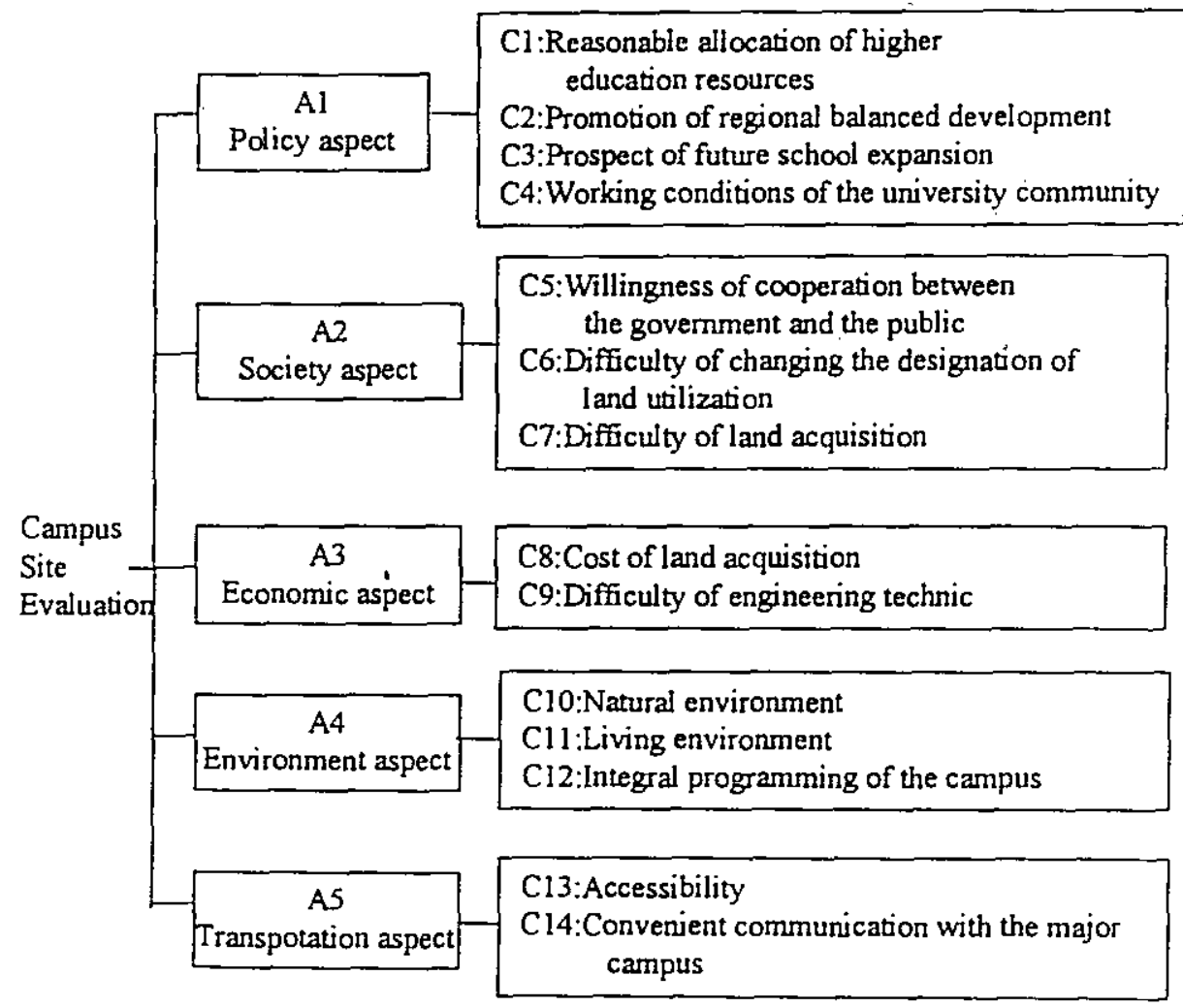

Figure 2. The Evaliation Hierarchy Structure of the Canvassing Location for New Campus Site

\subsubsection{Performance evaluation of canvassing locations}

Based upon these forgoing criteria and measurement manners, this study will evaluate the performance value with its focus laid on the four better canvassing locations. Those that can be measured by fixed size are indicated with its original unit, and those that are of constant measurement size are given $A, B, C, D$, and $E$ five levels for quantification administration. In addition, the evaluation results of the superior and inferior relationships among $A>B>C>D>E$ frve levels are as shown in Table 1 . 
Table 1

Performance Evaluation of Canvassing Locations for New Campus Site

\begin{tabular}{|c|c|c|c|c|c|}
\hline \multirow[t]{2}{*}{ Aspects } & \multirow[t]{2}{*}{ Criterias } & \multicolumn{4}{|c|}{ Canvassing Locations } \\
\hline & & $\mathrm{Ll}$ & $\mathrm{L} 2$ & $\mathrm{L3}$ & $\mathrm{LA}$ \\
\hline \multirow[t]{4}{*}{$\mathrm{Al}$} & $\mathrm{Cl}$ & $29(\mathrm{Km})$ & $18(\mathrm{Km})$ & $12(\mathrm{~km})$ & $98(\mathrm{~km})$ \\
\hline & $\mathrm{C} 2$ & B & $\mathrm{B}$ & B & $A$ \\
\hline & $\mathrm{C} 3$ & $42.0(\mathrm{ha})$ & $163.6(\mathrm{ha})$ & $66.0(\mathrm{ha})$ & 131.5 (ha) \\
\hline & $\mathrm{C} 4$ & $\mathrm{C}$ & $A$ & $\mathrm{C}$ & A \\
\hline \multirow[t]{3}{*}{ A2 } & $\mathrm{C} 5$ & $\mathrm{~B}$ & $\bar{B}$ & $\mathrm{~A}$ & A \\
\hline & C6 & $\mathrm{E}$ & B & B & B \\
\hline & $\mathrm{C7}$ & D & $\mathrm{B}$ & $\mathrm{E}$ & D \\
\hline \multirow[t]{2}{*}{ A3 } & C8 & $24,021,000$ & $37,945,360$ & $97,208,580$ & $52,509,534$ \\
\hline & $\mathrm{C} 9$ & $\mathrm{D}$ & $\mathrm{C}$ & $\mathrm{C}$ & B \\
\hline \multirow[t]{3}{*}{ A4 } & $\mathrm{ClO}$ & $\mathrm{C}$ & B & $\mathrm{C}$ & A. \\
\hline & $\mathrm{Cll}$ & C & A & A & D \\
\hline & $\mathrm{C} 12$ & A. & $\mathrm{C}$ & $\mathrm{C}$ & D \\
\hline \multirow[t]{2}{*}{ A5 } & $\mathrm{C} 13$ & $\mathrm{C}$ & A & A & $\mathrm{D}$ \\
\hline & $\mathrm{Cl} 4$ & $90(\min )$ & $35(\mathrm{~min})$ & $30(\min )$ & $180(\min )$ \\
\hline
\end{tabular}

\subsubsection{Investigation and analysis of preference structure}

To evaluate these four better canvassing locations, this study has invited altogether twenty-seven top executives of the school and professors to make up a decision making group. Then, this study will first design, in accordance to the formulated evaluation criteria listed in the preceding section, pairwise comparison questionnaire after AHP and conduct face-to-face interview, after which, these twenty seven interviewees start to fill in questionnaire after they have thoroughly understood the probiems. At the meantime, the weights of each hierarchical element are keyed into computer for calculation, and results will be shown on computer after these weights have passed verification check. Afterwards, interviewees will reconfirm their preference structure, and that comes to the end of the investigation.

As indicated in resuits of the chuster analysis, there is no difference in terms of values among first-rate executives, second-rate executives and professors, except that the preference structure of $\mathrm{P} 25$ (second cluster) is different. Besides, the individuals P4 and $\mathrm{P} 5$ in charge of this case have not been classified into the same cluster, which tells that though there is in-depth understanding to the practical problem is no predesignated bias has afoot.

As can learned from the preceding anaiysis, the preference structure and backgrounds of the decision making group members are not evidently related, it then indicates that the group decision making model applied on this case analysis is very useful for citation in the decision making. 


\subsubsection{The decision of the best compromise location}

According to the previously evaluated performance measures and preference structure, this study has utilized permutation method to conduct multicriteria evaluation. The $L 2$ has been given the highest ranking by 24 out of 27 evaluators. As shown in Table 2, the pre-designated campus is the choice. Furthermore, this study employs group decision making model associated with compromise programming to identify the best compromise location.

This study has made up a decision making group that includes professors, and twenty-seven administrative executives and professors, then compromise programming is employed for resolution in accordance to the results of ranking (as shown in table 2). And the results of resolution of these three situation are entirely consistent, which are indicated as following:

Table 2

The Multicriteria Evaluation Results of the Canvassing Locations

\begin{tabular}{lcccc}
\hline Decision-makers & \multicolumn{4}{c}{ Ranking of Canvassing Locations } \\
\cline { 2 - 5 } & L1 & L2 & L3 & L4 \\
\hline P1* & 4 & 1 & 3 & 2 \\
P2 & 4 & 1 & 3 & 2 \\
P3* & 4 & 1 & 3 & 2 \\
P4 & 4 & 1 & 3 & 2 \\
P5 & 4 & 1 & 3 & 1 \\
P6 & 4 & 2 & 3 & 2 \\
P7 & 4 & 1 & 3 & 2 \\
P8 & 4 & 1 & 3 & 2 \\
P9 & 4 & 1 & 3 & 2 \\
P10 & 4 & 1 & 3 & 2 \\
P11 & 4 & 1 & 3 & 2 \\
P12 & 4 & 1 & 3 & 2 \\
P13* & 4 & 1 & 3 & 2 \\
P14* & 2 & 1 & 4 & 3 \\
P15* & 4 & 1 & 3 & 2 \\
P16* & 2 & 1 & 4 & 3 \\
P17 & 4 & 1 & 3 & 2 \\
P18* & 4 & 1 & 3 & 2 \\
P19 & 2 & 1 & 4 & 3 \\
P20 & 4 & 1 & 3 & 2 \\
P21 & 3 & 1 & 4 & 2 \\
P22* & 4 & 1 & 3 & 2 \\
P23* & 4 & 2 & 3 & 1 \\
P24* & 4 & 1 & 3 & 2 \\
P25* & 2 & 1 & 4 & 3 \\
P26 & 4 & 2 & 3 & 1 \\
P27* & 4 & 1 & 3 & 2 \\
\hline ps: ${ }^{*}$ Mark stands for professor, and the others represent as senior officers.
\end{tabular}


It can be learned from the forgoing analysis that $\mathrm{L} 2$ is the best compromise location among those pre-designated campus sites for Taipei Institute of Technology: and should be given priority of consideration. $L A$ is of the second best compromise location, and can be taken as the stand-by location.

\section{Conclusions and recommendations}

Public facility location problems are issues that seek how to allocate public facility at the proper spots of places so as to obtain the optimal objective, and the decisions to locate the optimal locations for MRT (Mass Rapid Transit) station, high-speed railway station, highway interchange, nuclear power plant, gas tank, gas station, police station, fire engine station, emergency medical center, gymnasium, newly-established college and university are of the kind of decision making.

In view of the public facility location problem, this study will first review relevant literatures so as to know the characteristics of the problem and grasp the development trend of the analysis method. Next, multiobjective decision making methods are exploited so as establish analysis model, and the evaluation and selection of new campus sites for Taipei Institute of Technology are being employed to illustrate the case analysis. After which, this study has concluded, upon its results of study, the following conclusions and recommendations.

\subsection{Conclusions}

1.The multiobjective decision making analysis model for public facility location and its advantages.

This study will base on the characteristics of public facility location problem and contrive multiobjective decision making analysis model for public facility location in a three stages analysis structure. The first stage is of the screening model which takes non-compensable criterion as its screening requirement; the second stage is of the multicriteria evaluation model which utilizes analytic hierarchy process (AHP) to investigate the preference structure of the decision makers, then permutation method is employed to compensate several compensable criteria; the third stage is of group decision making model which uses compromise programming to obtain the best compromise location.

The advantages of this model can be concluded as following:

(1) Through the operation of screening model, some infeasible locations are first eliminated, and that will further simplify the problem scale of the multicriteria evaluation model.

(2) This study has integrated AHP and permutation to administer jointly multicriteria evaluation model, which will not demonstrate the robustness advantage of permutation method but also make up its shortcoming in the regard of weight analysis, as a result, the evaluation outcome rendered will be more reliable. 
(3) One economist once said, "faulty decision making can be more terrifying than corruption." Any individual who only relies on his will to act is mostly to achieve prejudiced result. As a matter of act, only through the manner of group decision making can help to integrate diverse opinions and obtain compromise solution, thus elevating the quality of decision making.

(4) Complete aspects are being taken into account when the three stages of multiobjective decision making analysis model is utilized to handle decision making problem, besides, programmer as well as decision maker have rightly played their roles in the analysis procedures, thus, it is of reasonable and robust decision making analysis model. The analyzed result can, on one hand, offer itself as the best compromise solution, it can also offer the second best compromise solution as well as with decision maker with citation to the optimal solution of each of the group decision making members. It is, therefore, of auxiliary decision making tool.

\section{Result of case analysis}

This study uses the evaluation and selection of the new campus site for Taipei Institute of Technology to illustrate its case analysis, and the analyzed result is as following:

1. Of the twenty-six spots of area designated to be the new campus sites, four better canvassing locations have been selected after the operation of the screening model: L1, L2, L3, and L4.

2. These four better canvassing locations under the consideration of five aspects as policy, society, economic, environment, and transportation total fourteen criteria. And the results of the decision making group, which include fifteen first-rate executives, twelve second rate executives and professors totaling twenty-seven members, has reached the following compromise ranking:

(1) First prionity: L2

(2) Second priority: LA

(3) Third priority: L3

(4) Fourth prionity: Ll

\subsection{Recommendations}

1. According to the case analyzed result, this study suggests that Taipei Institute of Technology and related educational authorities should award L2 with the highest priority of consideration when they are to select new campus site for the school, while L4 is designated as the stand-by choice.

2. The analyzed result of this case study is highly valuable for citation in decision making, and it suggests related educational authorities to base on this analysis structure to evaluate and select new campus site for college and university, also the model can bè referred to by other newly-established or upgraded college or university. 
3. The multiobjective decision making analysis model contrived in this study for public facility enjoys such advantages as robustness and reasonableness. Related government authorities are advised to follow this structure to decide the location for the public location problem, such as MRT station, high-speed railway station, highway: interchange, nuclear power plant, gas tank, gas station, police station, fire engine station, emergency medical center, gymnasium and so on. Appropriate evaluation criteria are formulated in view of the practical problem, and suitable candidates are invited take part in the decision making group so as to handle ever increasing complex problems that aspects as policy, technology, economic, society, environment, and transportation. It is hoped that the decision making quality of public affairs can be elevated and spirit of democracy realized.

\section{References}

[1] Zeleny, M., Mutilple Criteria Decision Making, McGraw-Hill,New York, 1982.

[2] Keeney, R.L., and Nair, K, "Selecting Nuclear Power Plant Sites in the Pacific Northwest Using Decision Analysis", in Bell et al. (eds), Conflicting Objectives in Decisions, Wiley, New York, 1977, 298-322.

[3] Komoda, N.et al., "An Innovative Approach to System Requirements Analysis by Using Structure Modelling Method", IEEE, 1981, 305-313.

[4] Saaty, T.L., The Analytic Hierarchy Process, McGraw-Hill, New York, 1980.

[5] MacCrimmon, K. R, " Improving the System Desing and Evaluation Process by the Use of Trade-off Information: An Application to Northeast Corridor Transportation Planning", RM-5877-DOT, The Rand Corportaion, Santa Monica, Ca., 1969.

[6] Baker, J. et al., "An Application of Multiattribute Utility Theory to the Planning of Emergency Medical Services", Socio-Econ. Plan. Sci., 18/4 (1984) 273-280.

[7] Barda, O.H., Dupuis, J., and Lencioni, P.," Multicriteria Location of Thermal Power Plants", European Journal of Operational Research, 45 ,(1990), 332-346.

[8] Bhaskaran, S., and Turnquist, M.A, "Multiobjective Transportation Considerations in Multiple Facility Location", Transportation Research, 24A/2 (1990) 139-148.

[9] Cohon, J. L., and Eagles, T.W," Analysis of Nuclear Reactor Siting Policy Using Multiobjective Programming", in: Hansen, P.(ed.), Essays and Surveys on Multiple Criteria Decision Making. 1983, New York: Springer-Verlag.

[10] Flynn, J., and Ratick, S. , "A Multiobjective Hierarchical Covering Model for the Essential Air Services Program", Transportation Science, 22/2 (1988), 139147.

1 [11] Gilbert, K.C. , Holmes, D.D. , and Rosenthal, RE, "A Multiobjective Discrete Optimization Model for Land Allocation", Management Science, 31/12 (1985), 1509-1522.

[12] Hansen, P. et al. , "Single Facility Location on Networks", In:Martello, S. et al.(ed.), Surveys in Combinatorial Optimization, New York: Elsevier Science Publishers, 1987,113-145.

[13] Kathawala, Y., and Gholamnezhad, H. , "New Approach to Facility Locations Decisions", Int. J. Systems Sci., 18/2,1987, 389-402. 
[14] Revelle, C. , Cohon, J.L. , and Shobrys, D. , "Multiple Objectives In: Facility Location: A Review", in: Morse, J.N. (ed.), Organizations: Multiple Agents with Multiple Criteria, New York: Springer-Verlag, 1981,320-337.

[15] Schilling, D.A. , "Dynamic Location Modeling fór Public-Sector Facilities: A Multicriteria Approach", Decision Science, 1980, 11:714-726.

[16] Tone, K. and Yanagisawa, S. , "Site Selection for a Large Scale Integrated Circuits Factory", in:Golden,B.L. et al.(eds), The Analytic Hierarchy Process: Applications and Studies, New York: Springer-Verlag, 1989, 242-250.

[17] Voogd, H. , "Multicriteria Evaluation for Urban and Regional Planning", London: Pion Limited, 1983.

[18] Zografos, KG. , "Multiobjective Hierarchical Model for Locating Public Facilities on a Transportation Network: A Goal Programming Approach", Ph. D. Dissertation, The University of Connecticut, 1986. 